\begin{tabular}{|c|c|}
\hline Title & A novel copper(II) coordination at His186 in full-length murine prion protein \\
\hline Author(s) & $\begin{array}{l}\text { W atanabe, Y asuko; Hiraoka, Wakako; Igarashi, Manabu; I to, Kimihito; Shimoyama, Y uhei; Horiuchi, Motohiro; } \\
\text { Y amamori, T ohru; Y asui, Hironobu; Kuwabara, Mikinori; I nagaki, Fuy uhiko; I nanami, O samu }\end{array}$ \\
\hline Citation & $\begin{array}{l}\text { Biochemical and Biophysical Research Communications, 394(3), 522-528 } \\
\text { https://doi.org/10.1016/j.bbrc.2010.03.003 }\end{array}$ \\
\hline Issue Date & $2010-0409$ \\
\hline Doc URL & http:/hdl.handle.net/2115/43092 \\
\hline Type & article (author version) \\
\hline File Information & BBRC394-3_522-528.pdf \\
\hline
\end{tabular}

Instructions for use 


\section{A novel copper(II) coordination at His186 in full-length murine prion protein}

\section{Yasuko Watanabe ${ }^{\mathrm{a}}$, Wakako Hiraoka ${ }^{\mathrm{b}}$, Manabu Igarashic ${ }^{\mathrm{c}}$, Kimihito Ito ${ }^{\mathrm{c}}$, Yuhei \\ Shimoyama $^{\mathrm{d}}$, Motohiro Horiuchi ${ }^{\mathrm{e}}$, Tohru Yamamori ${ }^{\mathrm{a}}$, Hironobu Yasui ${ }^{\mathrm{a}}$, Mikinori Kuwabara $^{a}$, Fuyuhiko Inagaki ${ }^{\mathrm{f}}$ and Osamu Inanami ${ }^{{ }^{*}}$}

${ }^{\mathrm{a}}$ Laboratory of Radiation Biology and ${ }^{\mathrm{e}}$ Laboratory of Prion Diseases, Graduate School of Veterinary Medicine, Hokkaido University, Sapporo 060-0818, Japan

${ }^{\mathrm{b}}$ Laboratory of Biophysics, School of Science and Technology, Meiji University, Kawasaki 214-8571, Japan

${ }^{c}$ Department of Global Epidemiology, Hokkaido University Research Center for Zoonosis Control, Sapporo 001-0020, Japan.

${ }^{\mathrm{d}}$ Soft-Matter Physics Laboratory, Graduate School of Emergent Science, Muroran Institute of Technology, Muroran 050-8585, Japan

${ }^{\mathrm{f}}$ Laboratory of Structural Biology, Graduate School of Pharmaceutical Sciences, Hokkaido University, Sapporo 060-0812, Japan

*Corresponding author: Osamu Inanami, Ph.D.

Laboratory of Radiation Biology, Department of Environmental Veterinary Sciences, Graduate School of Veterinary Medicine, Hokkaido University, Kita 18-Jo Nishi 9-chome, Sapporo 060-0818, JAPAN

Tel: +81-11-706-5235

Fax: +81-11-706-7373

E-mail: inanami@vetmed.hokudai.ac.jp 


\begin{abstract}
To explore $\mathrm{Cu}(\mathrm{II})$ ion coordination by $\mathrm{His}^{186}$ in the C-terminal domain of full-length prion protein $(\mathrm{moPrP})$, we utilized the magnetic dipolar interaction between a paramagnetic metal, $\mathrm{Cu}(\mathrm{II})$ ion, and a spin probe introduced in the neighborhood of the postulated binding site by the spin labeling technique (SDSL technique). Six moPrP mutants, moPrP(D143C), $\operatorname{moPrP}(\mathrm{Y} 148 \mathrm{C}), \quad \operatorname{moPrP}(\mathrm{E} 151 \mathrm{C}), \quad \operatorname{moPrP}(\mathrm{Y} 156 \mathrm{C}), \quad \operatorname{moPrP}(\mathrm{T} 189 \mathrm{C}) \quad$ and $\operatorname{moPrP}(\mathrm{Y} 156 \mathrm{C}, \mathrm{H} 186 \mathrm{~A})$, were reacted with a methane thiosulfonate spin probe and a nitroxide residue (R1) was created in the binding site of each one. Line broadening of the ESR spectra was induced in the presence of $\mathrm{Cu}(\mathrm{II})$ ions in $\operatorname{moPrP}(\mathrm{Y} 148 \mathrm{R} 1), \operatorname{moPrP}(\mathrm{Y} 151 \mathrm{R} 1)$, $\operatorname{moPrP}(\mathrm{Y} 156 \mathrm{R} 1)$ and $\operatorname{moPrP}(\mathrm{T} 189 \mathrm{R} 1)$ but not $\operatorname{moPrP}(\mathrm{D} 143 \mathrm{R} 1)$. This line broadening indicated the presence of electron-electron dipolar interaction between $\mathrm{Cu}$ (II) and the nitroxide spin probe, suggesting that each interspin distance was within $20 \AA$. The interspin distance ranges between $\mathrm{Cu}(\mathrm{II})$ and the spin probes of $\operatorname{moPrP}(\mathrm{Y} 148 \mathrm{R} 1), \operatorname{moPrP}(\mathrm{Y} 151 \mathrm{R} 1)$, $\operatorname{moPrP}(\mathrm{Y} 156 \mathrm{R} 1)$ and moPrP(T189R1) were estimated to be $12.1 \AA$, $18.1 \AA$, $10.7 \AA$ and $8.4 \AA$, respectively. In moPrP(Y156R1,H186A), line broadening between $\mathrm{Cu}(\mathrm{II})$ and the spin probe was not observed. These results suggest that a novel $\mathrm{Cu}(\mathrm{II})$ binding site is involved in His186 in the Helix 2 region of the $\mathrm{C}$-terminal domain of $\operatorname{moPrP}^{\mathrm{C}}$.
\end{abstract}

Key words: prion protein; $\mathrm{Cu}(\mathrm{II})$; C-terminal domain; ESR; SDSL; MTSSL; interspin distance; dipolar interaction; histidine residue 


\section{Introduction}

Transmissible spongiform encephalopathies (TSEs), or prion diseases, are a group of fatal neurodegenerative disorders including Creutzfeldt-Jacob disease (CJD), Gerstmann-Sträusler-Scheinker (GSS) syndrome, fatal familial insomnia (FFI) and kuru in humans, scrapie in sheep and bovine spongiform encephalopathy (BSE) in cattle [1]. The prion diseases are considered to be caused by the conformational conversion of a normal cellular prion protein $\left(\mathrm{PrP}^{\mathrm{C}}\right)$ into the abnormal (scrapie-like and $\beta$-sheet-rich) form of prion protein $\left(\mathrm{PrP}^{\mathrm{Sc}}\right)$ in endosomes, the main intracellular acidic organelles [2]. The precise mechanism of conversion from $\operatorname{PrP}^{\mathrm{C}}$ to $\mathrm{PrP}^{\mathrm{Sc}}$ is still unknown. However, accumulating evidence suggests that $\mathrm{Cu}(\mathrm{II})$ ions associated with $\mathrm{PrP}^{\mathrm{C}}$ play an important role in the conversion process from $\operatorname{PrP}^{\mathrm{C}}$ to $\operatorname{PrP}^{\mathrm{Sc}}[3,4]$.

Mammalian $\operatorname{PrP}^{\mathrm{C}}$ is a ubiquitous glycoprotein attached to the plasma membrane via a glycosyl phosphatidylinositol (GPI) anchor and localized in membrane lipid rafts [5]. Lipid rafts, which are rich in sphingolipids and cholesterol, are associated with endocytosis. The mature prion protein of the mouse (moPrP) consists of 208 amino acids (residues 23-231). The structure of $\operatorname{PrP}^{\mathrm{C}}$ consists of a tertiary carboxy-terminal domain which contains three $\alpha$-helices (Helix1, Helix2 and Helix3) and two short anti-parallel $\beta$-sheets (Sheet1 and Sheet2) [6]. On the other hand, the N-terminal domain includes an octarepeat (OR) region (residues 61-91) containing multiple copies of the repeat PHGGGWGQ, which has high affinity for binding $\mathrm{Cu}(\mathrm{II})$ ions $[7,8]$. Through this domain does not contribute measurably to the manifestation of the 3D-structure as detected by one-dimensional proton-nuclear magnetic resonance (NMR) [9], some studies using the ESR technique have shown that binding four copper ions induces a unique structure in this region [10-12]. Weiss et al. proposed models of the $\mathrm{Cu}(\mathrm{II})$ binding structure in the octarepeat region of the full-length 
prion protein by using the combination of extended X-ray absorption fine spectroscopy (EXAFS), electron paramagnetic resonance (EPR) and electron nuclear double resonance (ENDOR) [12]. Furthermore, a fifth $\mathrm{Cu}(\mathrm{II})$ binding site with higher affinity was identified between 91 and 125 next to the octarepeat motif. The involvement of two histidine residues (H95 and H110) in the $\mathrm{Cu}(\mathrm{II})$ binding has been suggested [13-15]. Recent studies have proposed that a novel $\mathrm{Cu}(\mathrm{II})$ binding site is included in the $\mathrm{C}$-terminal tertiary regions of $\operatorname{PrP}^{\mathrm{C}}$ [16-18]. Brown et al. showed that the peptide fragment analogue of $\operatorname{PrP}\left(\operatorname{PrP} A c 180-193 \mathrm{NH}_{2}\right)$ is the $\mathrm{Cu}$ (II) binding motif in the $\mathrm{C}$-terminal region [17]. The binding site location of $\mathrm{Cu}(\mathrm{II})$ in the structured region of the protein is suggested to show the involvement of a histidine 187 residue in the human (histidine 186 residue in the mouse). Moreover, when using two shorter peptide fragments $\left(\operatorname{PrP} 180-193 \mathrm{NH}_{2}\right.$ and $\operatorname{PrP}$ Ac184-188NH ), the affinity of the Helix 2 fragment of PrP was higher than that for the octarepeat and PrP106-126 peptides [18]. However, there is no experimental evidence for the existence of a novel copper binding site in the intact C-terminal domain of the full-length prion protein.

Recently, to obtain information about the $\mathrm{pH}$-induced conformational changes, we employed cysteine-scanning site-directed spin labeling (SDSL) combined with electron spin resonance spectroscopy (ESR), and analyzed the $\mathrm{pH}$-induced mobility changes in one $\alpha$-helix (Helix1) and two $\beta$-sheets (Sheet1 and Sheet2) of mouse $\operatorname{PrP}^{\mathrm{C}}\left(\operatorname{moPrP}^{\mathrm{C}}\right)$ [19-22]. Our experimental data using cysteine-scanning spin labeling for 19 cysteine mutants of recombinant moPrP $\mathrm{P}^{\mathrm{C}}$ clearly demonstrated the presence of three $\mathrm{pH}$-sensitive sites in $\operatorname{moPrP}^{\mathrm{C}}$. SDSL-ESR has proven to be a useful technique for protein structural and motional analyses, such as determination of the secondary structure and its orientation, areas of tertiary interactions and domain mobility, which are impossible to obtain by NMR and X-ray crystallographic methods $[23,24]$. Furthermore, this SDSL-ESR technique is reported to be 
useful for characterization of the binding sites of various proteins with paramagnetic metal ions. Originally, this technique was established based on a theory for the distance-dependent relaxation effects on dipolar interactions between metal ions and nitroxide in a rigid lattice system as described by Leigh et al [25]. More recently, Hubbell and colleagues have demonstrated that the SDSL technique permits measurement of the distance between a nitroxide spin probe in $\mathrm{T} 7$ lysozyme and $\mathrm{Cu}(\mathrm{II})$ ion of under physiological conditions [26].

In the present study, to identify a novel $\mathrm{Cu}(\mathrm{II})$ ion binding site in the carboxy-terminal domain of full-length moPrP, we examined the distance between $\mathrm{Cu}$ (II) ion and a nitroxide spin probe in the amino acid residues neighboring the postulated metal binding site, histidine 186 in the mouse. In this SDSL experiment, the nitroxide side chain (R1) derived from a methane thiosulfonate spin label (MTSSL) was introduced into six mutants of recombinant mouse prion protein, $\operatorname{moPrP}(\mathrm{D} 143 \mathrm{C}), \operatorname{moPrP}(\mathrm{Y} 148 \mathrm{C}), \operatorname{moPrP}(\mathrm{E} 151 \mathrm{C}), \operatorname{moPrP}(\mathrm{Y} 156 \mathrm{C})$, moPrP(T189C) and moPrP(Y156C,H186A), which were substituted for a cysteine residue by site-directed mutagenesis (Fig. 1A).

\section{Materials and Methods}

\section{Construction of moPrP mutants}

cDNA encoding mouse PrP (residues 23-231) was cloned into BamHI/EcoRI sites of pRSETb as described previously $[19-22,27]$. In the plasmid encoding moPrP, four amino acid residues, D143, Y148, E151 in the H1 region, Y156 in the loop between H1 and S2 and T189 in the $\mathrm{H} 2$ region, were changed to cysteine residues for the labeling site as indicated in Fig. 1A using the PCR-based site-directed mutagenesis method described previously [19-22]. Oligonucleotides used for the mutagenesis were obtained from Sigma Genosys. The changes of these codons were confirmed using a CEQ8800 automated sequencer (Beckman Coulter, 
Inc.). Figure $1 \mathrm{~B}$ shows the $3 \mathrm{D}$ structure in the carboxy-terminal domain of $\operatorname{moPrP}(121-231)$ as reported by Riek et al. (PDB code: 1AG2) [6].

\section{Expression, Purification and Spin-Labeling of recombinant moPrP mutants}

The expression and purification of recombinant moPrP mutants were carried out as described previously [21-24]. To label the $\operatorname{moPrP}^{\mathrm{C}}$ mutants with (1-Oxyl-2,2,5,5-tetramethylpyrroline-3-methyl)methane thiosulfonate (MTSSL) (Toronto Research Chemicals, ON, Canada), a 10-fold molar excess of MTSSL was added to each protein and incubated overnight in the dark at $4^{\circ} \mathrm{C}$. The free MTSSL was removed from the protein using a microdialyzer (Nippon Genetics). The protein concentration was quantified with the Lowry protein assay using BSA as a standard [28]. The final protein purity was confirmed by sodium dodecyl sulfate polyacrylamide gel electrophoresis (SDS-PAGE) and was at least 98\% pure. The positions of D143R1, Y148R1, E151R1, Y156R1, H186 and T189R1 in the 3D structure of the prion C-terminal region are shown in Fig. 1B.

\section{ESR spectroscopy and distance calculation}

Details of the ESR spectroscopy methods have been published elsewhere [19-22]. The neutralization of the sample solution was carried out by dialysis of the sample against $10 \mathrm{mM}$ HEPES buffer ( $\mathrm{pH} \mathrm{7.5)} \mathrm{and} \mathrm{20 \%} \mathrm{glycerol.} \mathrm{ESR} \mathrm{spectra} \mathrm{were} \mathrm{recorded} \mathrm{in} \mathrm{a} \mathrm{quartz} \mathrm{flat} \mathrm{cell}$ (RST-DVT05; $50 \mathrm{~mm}$ x $4.7 \mathrm{~mm}$ x $0.3 \mathrm{~mm}$, Radical Research) for spin-labeled samples of 20 $\mu \mathrm{M}$ moPrP ${ }^{\mathrm{C}}$ with each concentration of $\mathrm{CuCl}_{2}$ from $0 \mu \mathrm{M}$ to $160 \mu \mathrm{M}$ using a JEOL-RE X-band spectrometer (JEOL) with a cylindrical TE011 mode cavity (JEOL). All ESR spectra were obtained at $-10^{\circ} \mathrm{C}$, controlled by a temperature controller (ES-DVT4, JEOL) under the following conditions: $5 \mathrm{~mW}$ incident microwave power, $100 \mathrm{kHz}$ modulation frequency, 0.2 
mT field modulation amplitude, and $20 \mathrm{mT}$ scan range. In these conditions, containing $20 \%$ glycerol, the sample did not freeze. The distance between the nitroxide probe and bound $\mathrm{Cu}(\mathrm{II})$ was examined by measuring the intensity decrease of the ESR signal $\left(\mathrm{M}_{\mathrm{l}}=0\right.$, central component) of the spin-labeled $\mathrm{PrP}$ on addition of $\mathrm{Cu}$ (II) [26-27]. The distance, $r$, was calculated from following equation:

$$
r=\left[\left(\mathrm{g} \beta \mu^{2} \tau\right) /(\hbar C)\right]^{1 / 6}
$$

where the constant $g$ is the electronic $g$ factor for the nitroxide radical, $\beta$ is the Bohr magneton and $\mathrm{m}$ and $\tau c$ are the magnetic moment and the electron-spin relaxation time of $\mathrm{Cu}(\mathrm{II})$, respectively. $\tau_{c}=3 \times 10^{-9} \mathrm{~s}$ was used for the complexed $\mathrm{Cu}(\mathrm{II})$ [26]. $\delta \mathrm{H}_{0}$ is the unbroadened natural linewidth in the absence of the $\mathrm{Cu}(\mathrm{II})$ obtained from center $\left(\mathrm{M}_{\mathrm{I}}=0\right)$ line of the ESR spectrum and $C$ is the dipolar interaction coefficient for the measured spectrum. The value of $\mathrm{C} / \delta \mathrm{H}_{0}$ was obtained from the ratio of the broadened to unbroadened amplitude $\left(I / I_{0}\right)$ of the ESR spectrum of the spin label in the presence of paramagnetic ion using the graph reported by Voss et al. (1995) for labile motion in solution (rigid lattice care) [26].

\section{Computer simulation}

Molecular modeling was performed using the structure of mouse PrP (PDB code 1AG2) [6] to determine the most probable orientation of the MTSSL spin label. After mutating an amino acid to MTSSL-labeled cystein in silico, the structure was energy-minimized using the CHARMM19 force field in the CHARMM program [29]. Then, a Monte Carlo search was performed to find the lowest energy conformation for the spin label [30]. The topology and force field parameters for the MTSSL spin label were downloaded from the website of Fajer Lab (http://www.sb.fsu.edu/ fajer/Programs/Molecular_Modelling/Molecular_Modelling.htm), 
and were used for the calculation.

\section{Results and Discussion}

The N-terminal domain of prion protein includes an octarepeat (OR) region containing multiple copies of the repeat PHGGGWGQ, which has high affinity for binding four $\mathrm{Cu}(\mathrm{II})$ ion [8,9]. Furthermore, a fifth $\mathrm{Cu}(\mathrm{II})$ ion binding site was recently identified as a region involved in histidine 95 and histidine 110 in the neighborhood of the OR region. Some studies have suggested that $\mathrm{Cu}(\mathrm{II})$ binding to this fifth site is correlated with the conversion into a protease-resistant species and the increase of $\beta$-sheet conformation in $\operatorname{PrP}$ [13-15]. Recently, a novel sixth $\mathrm{Cu}(\mathrm{II})$ binding site in the C-terminal tertiary regions of $\operatorname{PrP}^{\mathrm{C}}$ was proposed in the model peptide and the truncated PrP protein [16-18]. To clarify whether the $\mathrm{Cu}(\mathrm{II})$ ion is correlated with the $\mathrm{C}$-ternimal region of the full length $\operatorname{moPrP}^{\mathrm{C}}$, we introduced a nitroxide spin-probe into the amino acid residues of the neighborhood of the postulated $\mathrm{Cu}$ (II) binding site (His186) in recombinant moPrP (rmoPrP) using the SDSL technique. If a $\mathrm{Cu}(\mathrm{II})$ ion is situated in the $\mathrm{H} 186$ residue and the distance between the $\mathrm{Cu}(\mathrm{II})$ ion and spin-probe is distributing within $20 \AA$, the line broadening of ESR spectrum originating from spin probe is reported to be induced by dipolar-dipolar interaction [26].

At first, we selected the threonine 189 residue for site-directed spin labeling to detect $\mathrm{Cu}(\mathrm{II})$, which would be located in histidine 186 residue because T189R1 and H186 postulated $\mathrm{Cu}$ (II) binding sites, were located in one pitch different position and the distance between these residues was very close, within about $5 \AA$. A mouse recombinant protein, moPrP(T189C), was purified, spin labeled, concentrated to $20 \mu \mathrm{M}$, and then measured by ESR in the absence or presence of $0,20,40,80,120$ and $160 \mu \mathrm{M} \mathrm{CuCl}_{2}$. Figure 2(a) shows the effects of $\mathrm{CuCl}_{2}$ on ESR spectra of moPrP(T189C), The intensity of ESR signals was 
decreased in a $\mathrm{CuCl}_{2}$ concentration-dependent manner, indicating that line broadening due to dipole-dipole interaction between $\mathrm{Cu}(\mathrm{II})$ and the nitroxide probe occurred. To obtain further information about the interaction between $\mathrm{Cu}(\mathrm{II})$ and the nitroxide spin probe, the ratios of the peak height (I) of the central $\left({ }^{14} \mathrm{~N}\right.$ hyperfine) component $\left(\mathrm{M}_{\mathrm{I}}=0\right)$ in the ESR spectrum with various concentrations of $\mathrm{CuCl}_{2}$ were plotted against that $\left(\mathrm{I}_{0}\right)$ without $\mathrm{CuCl}_{2}$ as shown in Fig. 2(b). The relative signal intensity $\left(\mathrm{I} / \mathrm{I}_{0} \times 100\right)$ decreased rapidly until the ratio of $[\mathrm{Cu}(\mathrm{II})]$ and $[\mathrm{PrP}]$ became 4 and then the relative intensity was maintained at about $20 \%$ at $[\mathrm{Cu}(\mathrm{II})] /[\mathrm{PrP}]=6$ and $[\mathrm{Cu}(\mathrm{II})] /[\mathrm{PrP}]=8$. This indicated that the prion proteins had multiple $\mathrm{Cu}$ (II) ion-binding sites and $160 \mu \mathrm{M} \mathrm{CuCl}_{2}([\mathrm{Cu}(\mathrm{II})] /[\mathrm{PrP}]=8)$ was sufficient to estimate the distance between $\mathrm{Cu}(\mathrm{II})$ ion coordinated at $\mathrm{H} 186$ and the nitroxide side chain.

Next, we examined the effects of $\mathrm{CuCl}_{2}$ on ESR spectra of moPrP(D143R1), $\operatorname{moPrP}(\mathrm{Y} 148 \mathrm{R} 1)$ and $\operatorname{moPrP}(\mathrm{E} 151 \mathrm{R} 1)$, which had the nitroxide probe at $\alpha$-Helix1, and moPrP(Y156R1), which had the nitroxide probe in the loop region between $\alpha$-Helix1 and $\beta$-Sheet2, as illustrated in Fig. 1(b). The ESR spectra of moPrP(D143R1), moPrP(Y148R1), $\operatorname{moPrP}(\mathrm{E} 151 \mathrm{R} 1)$ and moPrP(Y156R1) without (black line) and with $160 \mu \mathrm{M} \mathrm{CuCl}_{2}$ (red line) are shown in Fig. 3(a) - (d), respectively. Decreases of the intensity of the ESR spectra due to line broadening were clearly observed in $\operatorname{moPrP}(\mathrm{Y} 148 \mathrm{R} 1) \operatorname{moPrP}(\mathrm{E} 151 \mathrm{R} 1)$ and moPrP(Y156R1), indicating that $\mathrm{Cu}(\mathrm{II})$ was close $(<20 \AA)$ to sites Y148R1, E151R1 and Y156R1 under physiological conditions. The line broadening was not detected in moPrP(D143R1), indicating a long interspin distance (>20 ̊). There was a possibility that $\mathrm{Cu}$ (II) ion bonded to the sites other than His186, i.e., the octarepeat region from codon 60 to 90 [11-13] and the region between amino acids 95 and $110[14,15]$, were associated with the nitroxide spin probe of these recombinant prion proteins via an unexpected tertiary structure of $\mathrm{PrP}$ or intermolecular interaction. Therefore we tested the effect of $\mathrm{Cu}$ (II) on 
moPrP(Y156R1,H186A), which is a double mutation for disruption of the histidine residue for the $\mathrm{Cu}(\mathrm{II})$ binding site. As shown in Fig. 3(e), the reduction of ESR signal intensity was not found in the presence of $\mathrm{Cu}(\mathrm{II})$ ions in this double mutation, although the strong line broadening effect of $\mathrm{Cu}(\mathrm{II})$ ions was clearly observed in moPrP(Y156R1), as shown in Fig. 3(d). These data allowed us to conclude that a $\mathrm{Cu}(\mathrm{II})$ ion coordinated with His186 interacted with the nitroxide probe and produced line broadening of the nitroxide radical by dipole-dipole interaction.

To estimate the distance between the $\mathrm{Cu}$ (II) ion and the nitroxide probe, we calculated it based on the Redfield theory developed by Voss et al. [26]. Since the spectra of glassy PrP samples at $-10^{\circ} \mathrm{C}$ exhibit anisotropic shapes, values of $\mathrm{c}$, the dipolar interaction coefficient, were determined from the plot of $\mathrm{I} / \mathrm{Io}$ vs. $\mathrm{c} / \delta \mathrm{Ho}$ for rigid lattice $\mathrm{M}_{\mathrm{I}}=0$ line amplitude as described by Voss et al. [26]. As listed in Table 1, the distances from $\mathrm{Cu}(\mathrm{II})$ estimated for Y148R1, E151R1, Y156R1 and T189R1 ranged from $8.4 \AA$ to $18.1 \AA$ as summarized in Table 1. Figure 4(a)-(e) shows the molecular simulation used to determine the most probable orientation of the spin probe moiety created in each prion mutant and the approximate position of the $\mathrm{Cu}$ (II) ion if the histidine 186 residue is important as a novel $\mathrm{Cu}$ (II) ion binding site in the prion protein. To compare experimental data and these computer simulation data for the $\mathrm{Cu}$ (II) binding structure, we estimated the distance between the oxygen atom of spin-probe and the nitrogen atom, which are the $\mathrm{N} \delta$ and $\mathrm{N} \varepsilon$ positions in the imidazole ring of histidine residue186, respectively (as illustrated by Fig. 4 (f)), in each mutant prion protein. It was clearly demonstrated that each interspin distance was quite similar to the interatom distance shown Table 1. Our data strongly indicated that histidine residue 186 in Helix 2 was a novel $\mathrm{Cu}$ (II) binding site in the $\mathrm{C}$-terminal core region of prion protein. 
A recent study using molecular dynamic (MD) simulation indicated that the break of the salt bridge between Arg156 and Glu196 induced by the protonation of His187 in human prion protein (His186 in mouse prion protein) at acidic $\mathrm{pH}$ was the key event underlying the extension of the S2 region and the conversion to $\beta$-sheet-rich PrP [31]. Furthermore, His187 in the human is reported to be involved in a pathogenic mutation (H187R) associated with GSS syndrome, which implies a positively charged residue at position 187 [32]. This H187R mutation may induce the break of the salt bridge in a manner similar to that induced by protonation of His187 under acidic $\mathrm{pH}$. In the present study, we demonstrated a novel binding site for $\mathrm{Cu}$ (II) ion located in the internal regions of Helix 2 and Helix 3 , as shown in Fig. 4. Langella et al. proposed that His187 and Glu196 were the most probable candidates for binding residues of $\mathrm{Cu}(\mathrm{II})$ ion according to their computer simulation and that H187R mutation was related to altered $\mathrm{Cu}$ (II) binding [32]. These reports and our results suggested that this disruption of the interaction between $\mathrm{Cu}(\mathrm{II})$ ion and $\mathrm{PrP}^{\mathrm{C}}$ by a point mutation of His 187 in the human influenced the C-terminal core structure related to induction of prion diseases such as GSS syndrome.

In conclusion, the present cysteine-scanning SDSL-ESR study of full-length recombinant $\operatorname{moPrP}^{\mathrm{C}}$ provides experimental evidence that a sixth $\mathrm{Cu}(\mathrm{II})$ binding site exists in the C-terminal region of moPrP $\mathrm{P}^{\mathrm{C}}$, similarly to a previous study using some peptide fragments. This novel $\mathrm{Cu}(\mathrm{II})$ binding site is involved in histidine residue 186 in the Helix 2 region of the C-terminal domain of moPrP ${ }^{\mathrm{C}}$. The pathogenic mutation at this $\mathrm{Cu}(\mathrm{II})$ binding site may be correlated with conversion of $\mathrm{PrP}^{\mathrm{C}}$ to the pathogenic $\mathrm{PrP}^{\mathrm{Sc}}$ structure in GSS syndrome

\section{Acknowledgments}

We thank H. Tamayama and Y. Otoshima for ESR spectroscopy. This work was 
supported, in part, by Grants-in-Aid for Basic Scientific Research from the Ministry of Education, Culture, Sports, Science and Technology of Japan (No. 21380185, No2165106 [O.I.], No. 17580275, No. 17658126 [M.K.] and No. 21780267 [Y.T]), by Research Grants from the Program for the Center of Excellence of Zoonosis Control, Sapporo 060-0818, Japan [Y.W., O.I., M.H.] and The Akiyama Life Science Research Foundation [O.I.]

\section{References}

[1] S.B. Prusiner, Prions, Proc. Natl. Acad. Sci. USA 95 (1998) 13363-13383.

[2] S. Hornemann, R. Glockshuber, A scrapie-like unfolding intermediate of the prion protein domain PrP(121-231) induced by acidic pH, Proc. Natl. Acad. Sci. USA 95 (1998) 6010-6014.

[3] E. Quaglio, R. Chiesa, D.A. Harris, Copper converts the cellular prion protein into a protease-resistant species that is distinct from the scrapie isoform, J. Biol. Chem. 276 (2001) 11432-11438.

[4] N.-H. Kim, J.-K. Choi, B.-H. Jeong, J.-I. Kim, M.-S. Kwon, R. I. Carp, Y.-S. Kim, Effect of transition metals $(\mathrm{Mn}, \mathrm{Cu}, \mathrm{Fe})$ and deoxycholic acid (DA) on the conversion of $\mathrm{PrP}^{\mathrm{C}}$ to PrP $^{\text {res }}$, FASEB J. 19 (2005) 783-785.

[5] M. Vey, S. Pilkuhn, H. Wille, R. Nixon, S.J. DeArmond, E.J. Smart, R.G. Anderson, A. Taraboulos, S.B. Prusiner, Subcellular colocalization of the cellular and scrapie prion proteins in caveolae-like membranous domains, Proc. Natl. Acad. Sci. USA 93 (1996) 14945-14949.

[6] R. Riek, S. Hornemann, G. Wider, M. Billeter, R. Glockshuber, K. Wüthrich, NMR structure of the mouse prion protein domain $\operatorname{PrP}(121-231)$, Nature 382 (1996) 180-182 
[7] R.M. Whittal, H.L. Ball, F.E. Cohen, A.L. Burlingame, S.B. Prusiner, M.A. Baldwin, Copper binding to octarepeat peptides of the prion protein monitored by mass spectrometry, Protein Sci. 9 (2000) 332-343.

[8] G.S. Jackson, I. Murray, L.L.P. Hosszu, N. Gibbs, J.P. Waltho, A.R. Clarke, J. Collinge, Location and properties of metal-binding sites on the human prion protein. Proc. Natl. Acad. Sci. USA 98 (2001) 8531-8535.

[9] S. Hornemann, C. Korth, B. Oesch, R. Rieka, G. Widera, K. Wüthrich, R. Glockshubera, Recombinant full-length murine prion protein, $\mathrm{mPrP}_{(23-231)}$ : purification and spectroscopic characterization, FEBS Lett. 413 (1997) 277-281.

[10] C.S. Burns, E. Aronoff-Spencer, C.M. Dunham, P. Lario, N.I. Avdievich, W.E. Antholine, M.M. Olmstead, A. Vrielink, G.J. Gerfen, J. Peisach, W.G. Scott, G.L. Millhauser, Molecular features of the copper binding sites in the octarepeat domain of the prion protein, Biochemistry 41 (2002) 3991-4001.

[11] P. del Pino, A. Weiss, U. Bertsch, C. Renner, M. Mentler, K. Grantner, F. Fiorino, W. Meyer-Klaucke., L. Moroder, H. A. Kretzschmar, F. G. Parak, The configuration of the $\mathrm{Cu}^{2+}$ binding region in full-length human prion protein, Eur. Biophys. J. 36 (2007) 239-252.

[12] A. Weiss, P. del Pino, U. Bertsch, C. Renner, M. Mentler, K. Grantner, L. Moroder, H.A. Kretzschmarnd, F.G. Parak, The configuration of the $\mathrm{Cu}^{2+}$ binding region in full-length human prion protein compared with the isolated octapeptide, Vet. Microbiol. 123 (2007) 358-366.

[13] S. S. Hasnain, L. M. Murphy, R. W. Strange, J. G. Grossmann, A. R. Clarke, G. S. Jackson, J. Collinge, XAFS study of the high-affinity copper-binding site of human 
$\operatorname{PrP}_{(91-231)}$ and its low-resolution structure in solution, J. Mol. Biol. 311 (2001) 467-473.

[14] C.E.Jones, S.R. Abdelraheim, D.R. Brown, J.H. Viles, Preferential $\mathrm{Cu}^{2+}$ coordination by His96 and His111 induces $\beta$-sheet formation in the unstructured amyloidogenic region of the prion protein, J. Biol. Chem. 279 (2004) 32018-32027.

[15] F. Berti, E. Gaggelli, R. Guerrini, A. Janicka, H. Kozlowski, A. Legowska, H. Miecznikowska, C. Migliorini, R. Pogni, M. Remelli, K. Rolka, D. Valensin, G. Valensin, Structural and dynamic characterization of copper(II) binding of the human prion protein outside the octarepeat region, Chemistry 13 (2007) 1991-2001.

[16] G. M. Cereghetti, A. Schweiger, R. Glockshuber, S. Van Doorslaer, Electron paramagnetic resonance evidence for binding of $\mathrm{Cu}^{2+}$ to the $\mathrm{C}$-terminal domain of the murine prion protein, Biophys. J. 81 (2001) 516-25.

[17] D. R. Brown, V. Guantieri, G. Grasso, G. Impellizzeri, G. Pappalardo, E. Rizzarelli, Copper(II) complexes of peptide fragments of the prion protein. Conformation changes induced by copper(II) and the binding motif in C-terminal protein region. J. Inorg. Biochem. 98 (2004) 133-143.

[18] D. Grasso, G. Grasso, V. Guantieri, G. Impellizzeri, C. La Rosa, D. Milardi, G. Micera, K. Õsz, G. Pappalardo, E. Rizzarelli, D. Sanna, I. Sóvágó, Environmental effects on a prion's helix II domain: copper(II) and membrane interactions with PrP180-193 and its analogues, Chemistry 12 (2005) 537-547.

[19] O, Inanami, S. Hashida, D. Iizuka, M. Horiuchi, W. Hiraoka, Y. Shimoyama, H. Nakamura, F. Inagaki, M. Kuwabara, Conformational change in full-length mouse prion: a site-directed spin-labeling study. Biochem. Biophys. Res. Commun. 335 (2005) 785-792.

[20] Y. Watanabe, O. Inanami, M. Horiuchi, W. Hiraoka, Y. Shimoyama, F. Inagaki, M. 
Kuwabara, Identification of $\mathrm{pH}$-sensitive regions in the mouse prion by the cysteine-scanning spin-labeling ESR technique. Biochem. Biophys. Res. Commun. 350 (2006) 549-556.

[21] Y. Watanabe, W. Hiraoka, Y. Shimoyama, M. Horiuchi, M. Kuwabara, O. Inanami, Instability of familial spongiform encephalopathy-related prion mutants, Biochem. Biophys. Res. Commun. 366(2008):244-249.

[22] Y.W. Chiang, Y. Otoshima, Y. Watanabe, O. Inanami, Y. Shimoyama, Dynamics and local ordering of spin-labeled prion protein: an ESR simulation study of a highly pH-sensitive site, J. Biomol. Struct. Dyn. 26(2008):355-366.

[23] W.L. Hubbell, H.S. Mchaourab, C. Altenbach, M.A. Lietzow, Watching proteins move using site-directed spin labeling, Structure 4 (1996) 779-783.

[24] W.L. Hubbell, D.S. Cafiso, C. Altenbach, Identifying conformational changes with site-directed spin labeling, Nat. Struct. Biol. 7 (2000) 735-739.

[25] J.S. Leigh, Jr., ESR rigid-lattice line shape in a system of two interacting spins, J. Chem. Phys. 52 (1970) 2608-2612

[26] J. Voss, L. Salwiński, H.R. Kaback, and W.L. Hubbell, A method for distance determination in proteins using a designed metal ion binding site and site-directed spin labeling: evaluation with T4 lysozyme, Proc. Natl. Acad. Sci. USA 92 (1995) 12295-12299.

[27] C.L. Kim, A. Umetani, T. Matsui, N. Ishiguro, M. Shinagawa, M. Horiuchi, Antigenic characterization of an abnormal isoform of prion protein using a new diverse panel of monoclonal antibodies, Virology 320 (2004) 40-51.

[28] O.H. Lowry, N.J. Rosebrough, A.L. Farr, R.J. Randall, Protein measurement with the 
Folin phenol reagent, J. Biol. Chem. 193 (1951) 265-275.

[29] B.R. Brooks, R. E. Bruccoleri, B.D. Olafson, D.J. States, S. Swaminathan and Karplus M, CHARMM: a program for macromolecular energy, minimization and dynamics calculations J. Comput. Chem. 4 (1983) 187-217

[30] K, Sale, C, Sar, K.A. Sharp, K. Hideg and P.G. Fajer, Structural determination of spin label immobilization and orientation: a Monte Carlo minimization approach, J. Magn. Reson. 156, 104(2002)12

[31] E. Langella, R. Improta, V. Barone, Checking the pH-induced conformational transition of prion protein by molecular dynamics simulations: effect of protonation of histidine residues, Biophys. J. 87 (2004) 3623-3632.

[32] L. Cervenakova, C. Buetefisch, H.S. Lee, I. Taller, G. Stone, C.J. Gibbs Jr, P. Brown, M. Hallett, L.G. Goldfarb, Novel PRNP sequence variant associated with familial encephalopathy, Am. J. Med. Genet. 88 (1999), 653-656. 


\section{Figure Legends}

\section{Figure 1}

A schematic diagram of the site-directed spin labeling (SDSL) technique and the mutation site for SDSL-ESR on the 3D structure of $\operatorname{moPrP}^{\mathrm{C}}$. (a) The chemical reaction of the methanethiosulfonate spin-labeling reagent with the cysteine residue generates the nitroxide side chain $(\mathrm{R} 1)$ on $\operatorname{moPrP}^{\mathrm{C}}$. (b) The carboxy-terminal domain of moPrP ${ }_{(121-231)}$ and five mutation sites, D143, Y148, E151, Y156 and T189, for SDSL-ESR. The side chains of Y156, D143R1, Y148R1, E151R1, Y156R1 and T189R1, were superimposed on the 3D structure of moPrP reported in an NMR study (PDB code: 1AG2, ref. [7]).

\section{Figure 2}

The interaction between the $\mathrm{Cu}(\mathrm{II})$ ion and nitroxide spin probe on the ESR spectra of full-length moPrP(T189R1) and titration curve of reduction of ESR intensity by $\mathrm{Cu}(\mathrm{II})$. (a) The line broadening of ESR spectra originating from the spin probe in T189 due to the presence of various concentrations of $\mathrm{Cu}(\mathrm{II})(0,20,40,80,120$ and $160 \mu \mathrm{M})$. The molar ratio of $\mathrm{Cu}(\mathrm{II})$ ions against $[\mathrm{PrP}]([\mathrm{Cu}(\mathrm{II})] /[\mathrm{PrP}])$ is shown by the value to the left of each spectrum. (b) The ratios of peak height (I) of the peak-to-peak central component $\left(\mathrm{M}_{\mathrm{I}}=0\right)$ in $\mathrm{ESR}$ spectra of Y156R1 and T189R1 in the presence of various concentrations of $\mathrm{Cu}(\mathrm{II})$ against those $\left(\mathrm{I}_{0}\right)$ without $\mathrm{Cu}(\mathrm{II})$.

\section{Figure 3}

Effects of $\mathrm{Cu}(\mathrm{II})$ on ESR spectra of (a) $\operatorname{moPrP}(\mathrm{D} 143 \mathrm{R} 1)$ (b) $\operatorname{moPrP}(\mathrm{Y} 148 \mathrm{R} 1)$, (c) moPrP(Y151R1), (d) moPrP(Y156R1) and (e) moPrP(Y156R1,H186A). Each spin-labeled 
moPrP mutant was prepared as a $20 \mu \mathrm{M}$ concentration in 10mM HEPES buffer $(\mathrm{pH} 7.5)$ and $50 \%$ glycerol for ESR measurement. The line shapes of spectra were obtained in the absence (black line) and the presence (red line) of $160 \mu \mathrm{M} \mathrm{Cu}(\mathrm{II}) .([\mathrm{Cu}(\mathrm{II})] /[\mathrm{PrP}]=8)$. (f) The distance between the oxygen atom of spin-probe and the nitrogen atom, which are the $\mathrm{N} \delta$ and $\mathrm{N} \varepsilon$ positions in the imidazole ring of histidine residue 186 , respectively

\section{Figure 4}

The computer simulation structures of (a) $\operatorname{moPrP}(\mathrm{D} 143 \mathrm{R} 1)$ (b) $\operatorname{moPrP}(\mathrm{Y} 148 \mathrm{R} 1)$, (c) moPrP(Y151R1), (d) $\operatorname{moPrP}(\mathrm{Y} 156 \mathrm{R} 1)$ and (e) $\operatorname{moPrP}(\mathrm{T} 189 \mathrm{R} 1)$ by energy-minimized calculations using the CHARMM19 force field in the CHARMM program. The orientation of the spin probe was determined by the lowest energy conformation, which was estimated by a Monte Carlo search. From these computer simulation structures, the interatom distance between the oxygen atom of spin-probe and nitrogen atom, which are the $\mathrm{N} \delta$ and $\mathrm{N} \varepsilon$ positions in the imidazole ring of histidine residue186, respectively (as shown in schema as shown in (f)), is presented in Table 1. 
Table 1.

Interspin distance between oxygen atom of nitroxide probe and $\mathrm{Cu}$ (II) calculated by dipole-dipole interaction and interatomic distance between oxygen atom of nitroxide probe and nitrogen atom of His186 estimated by computer simulation.

\begin{tabular}{|c|c|c|c|}
\hline & \multirow{2}{*}{$\begin{array}{c}\text { Interspin distances }(\AA) \\
\mathrm{r}(-\mathrm{NO}-\mathrm{Cu})\end{array}$} & \multicolumn{2}{|c|}{ Interatomic distances $(\AA)$} \\
\hline & & r(-NO--N $\delta)$ & $\mathrm{r}(-\mathrm{NO} \cdot-\mathrm{N} \varepsilon)$ \\
\hline D143R 1 & $>20$ & 23.570 & 21.767 \\
\hline Y148R1 & 12.1 & 11.156 & 8.996 \\
\hline $\mathrm{E} 151 \mathrm{R} 1$ & 18.1 & 19.583 & 17.741 \\
\hline Y156R1 & 10.7 & 8.491 & 6.541 \\
\hline T189R1 & 8.4 & 3.016 & 4.989 \\
\hline
\end{tabular}


Figure 1

(a)

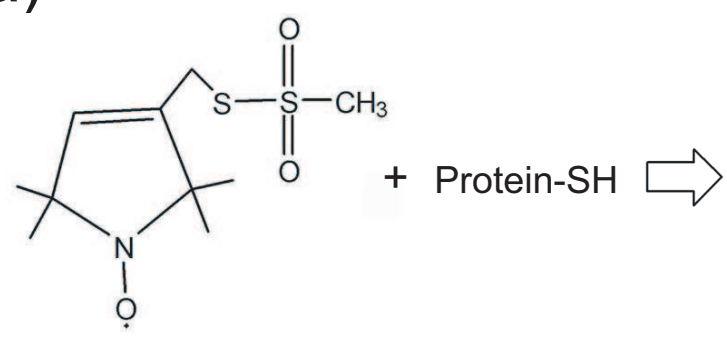

(1-Oxyl-2,2,5,5-tetramethylpyrroline-3methl)methanethiosulfonate (MTSSL)

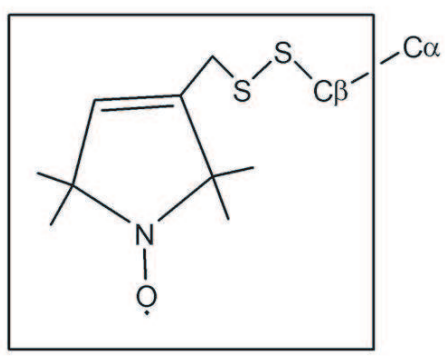

Slde chain (R1)

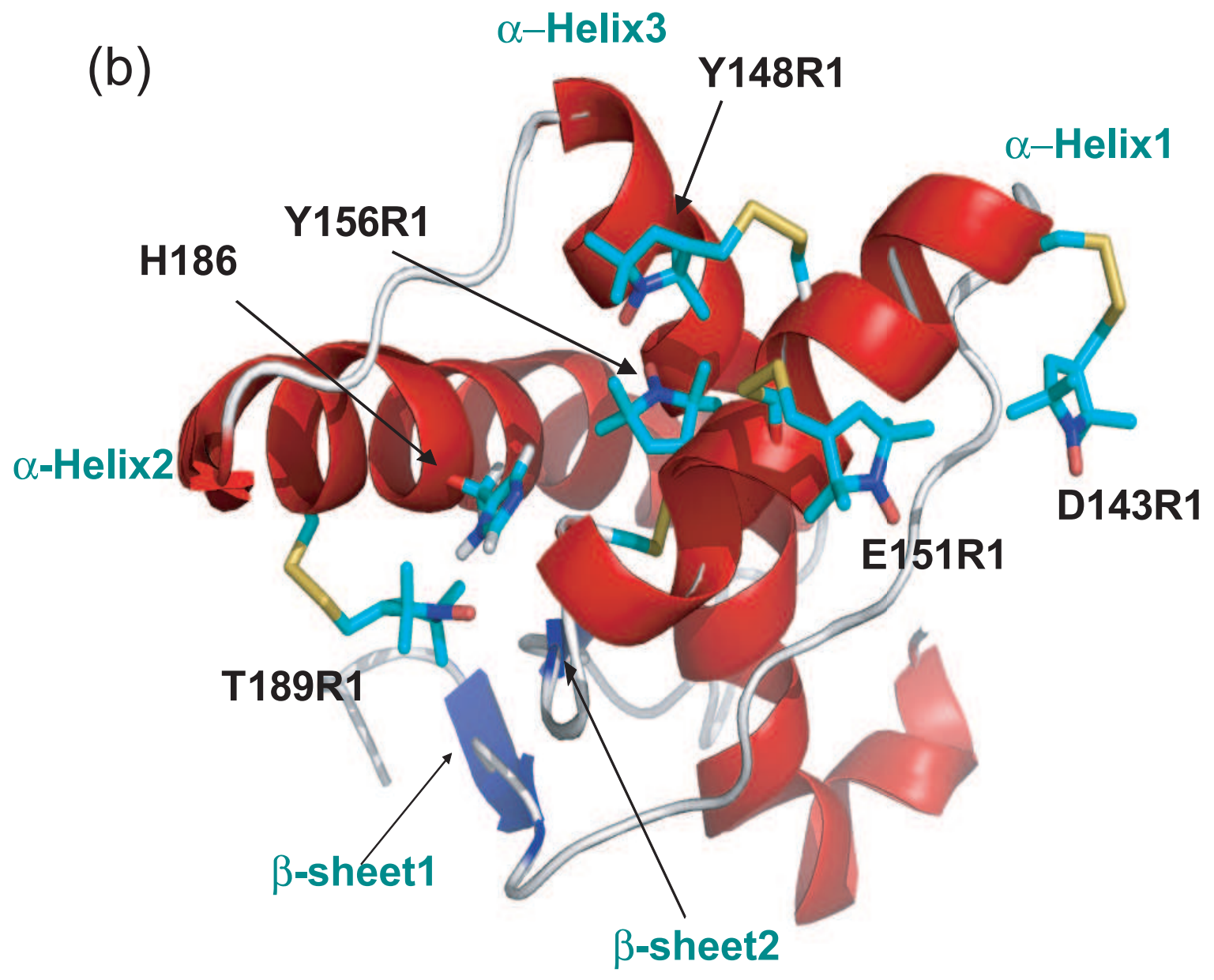


Figure 2

(a) T189R1

(b)

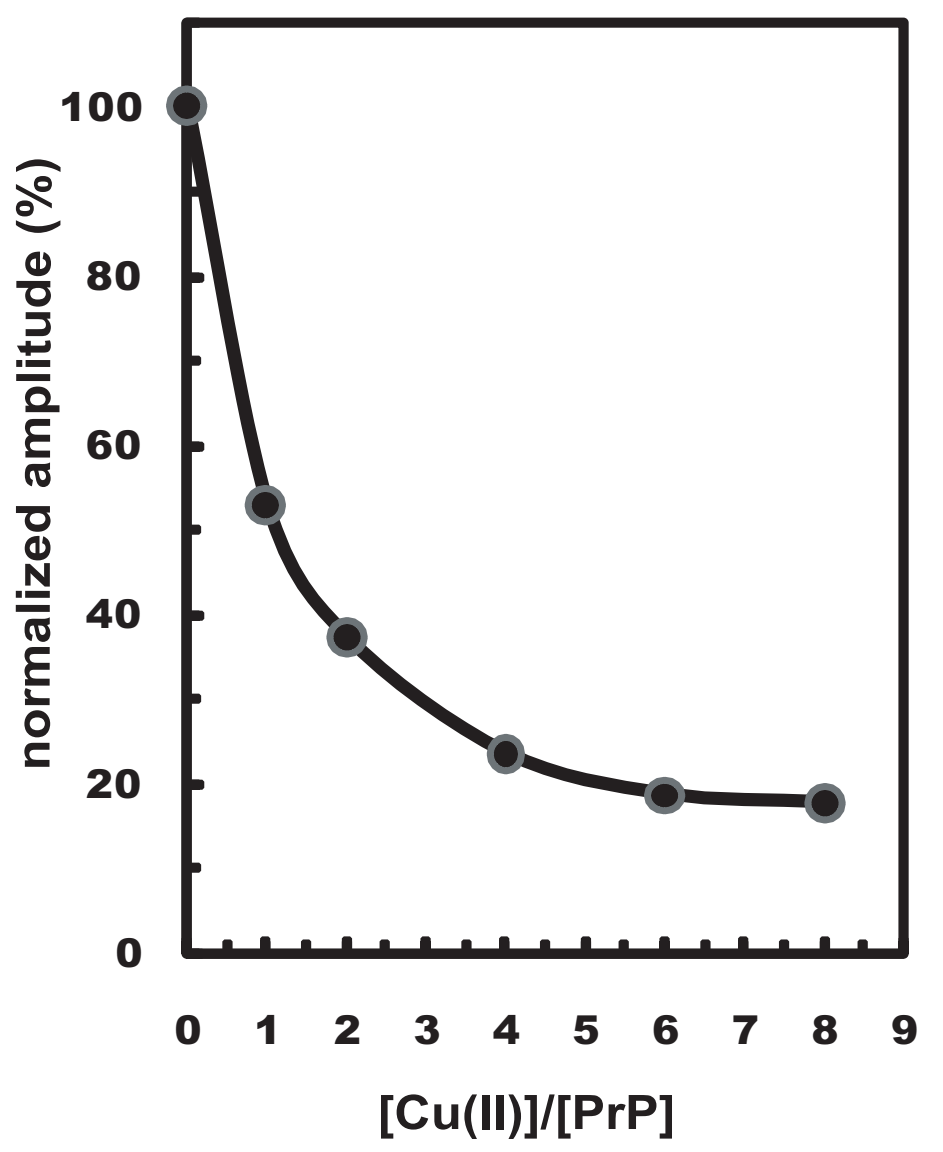

$[\mathrm{Cu}(\mathrm{II})] /[\mathrm{PrP}]=6$

$[\mathrm{Cu}(\mathrm{II})] /[\mathrm{PrP}]=8$

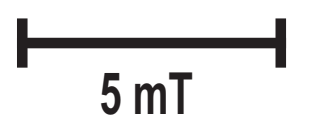

[Cu(II)]/[PrP] 
(a) D143R1

(b) Y148R1

(c) E151R1

(d) Y156R1
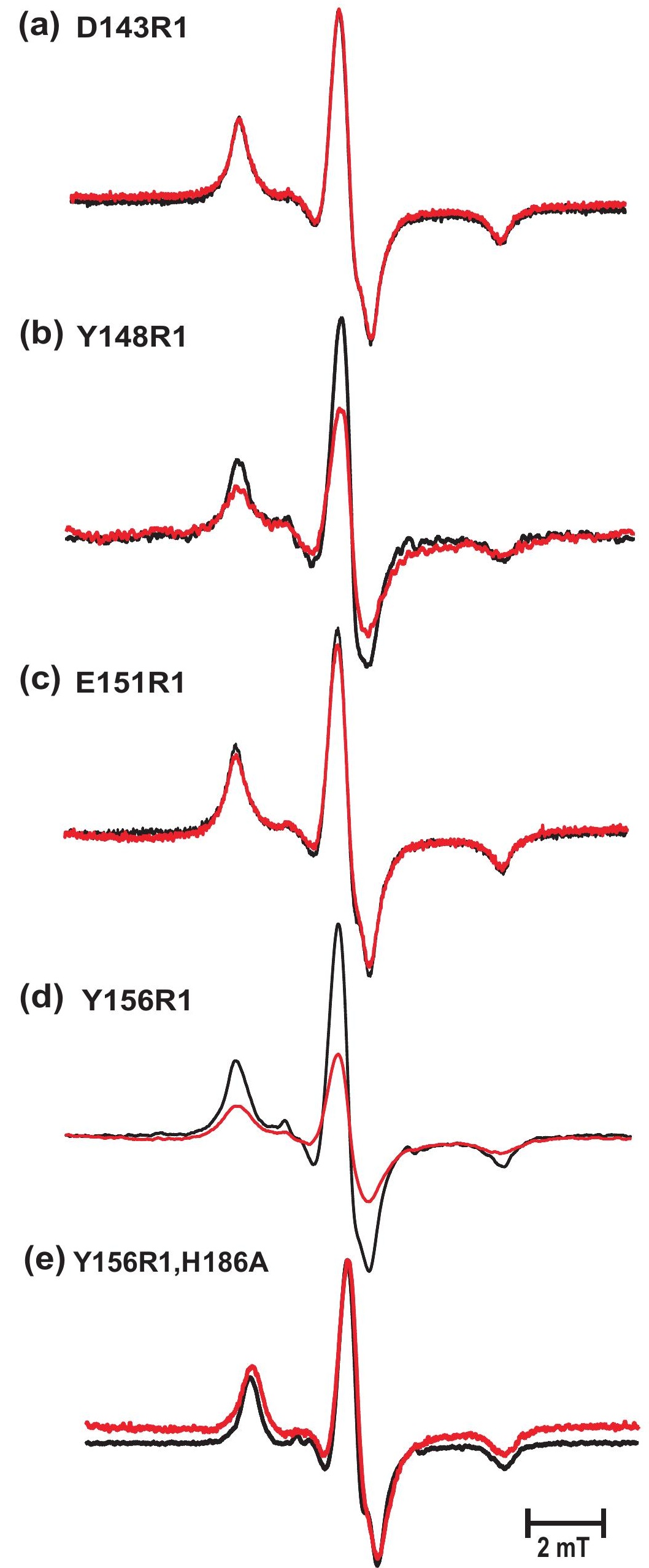
(a) D143R1

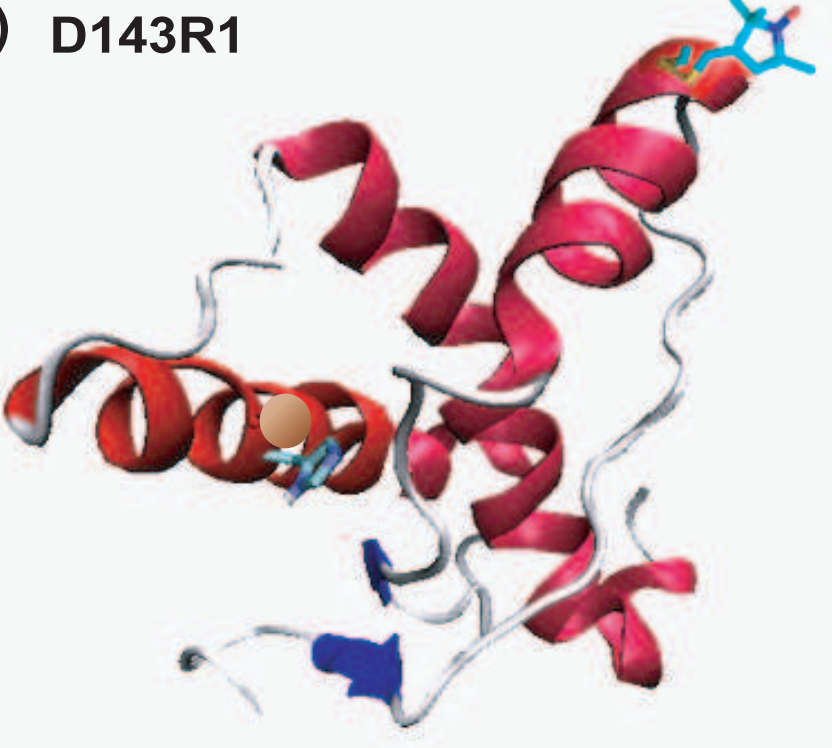

(c) E151R1

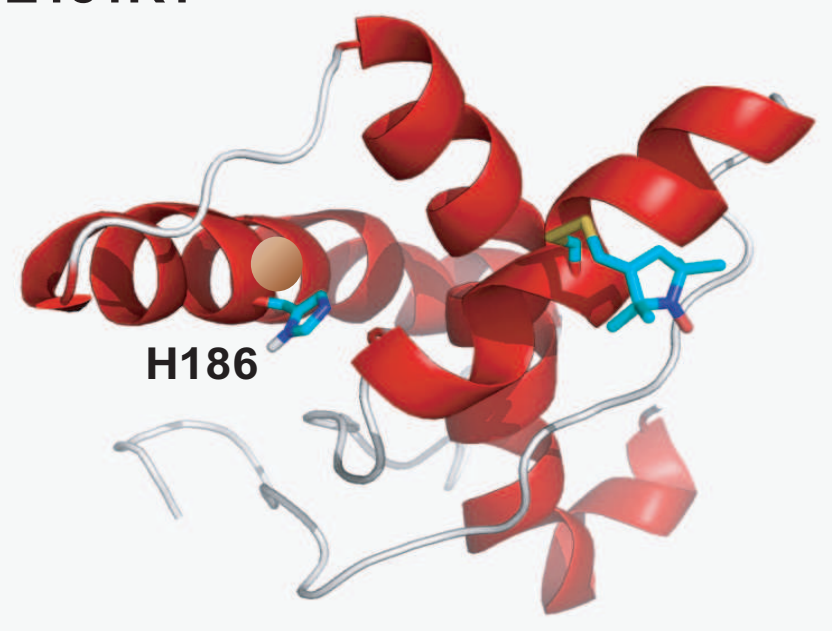

(e) T189R1

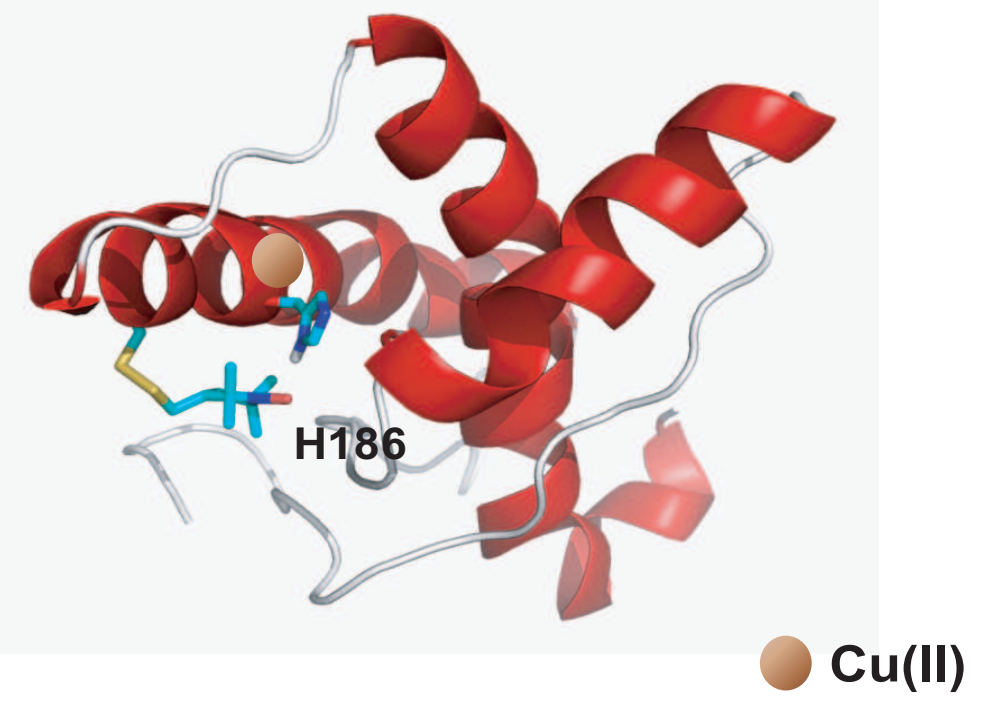

(b) Y148R1

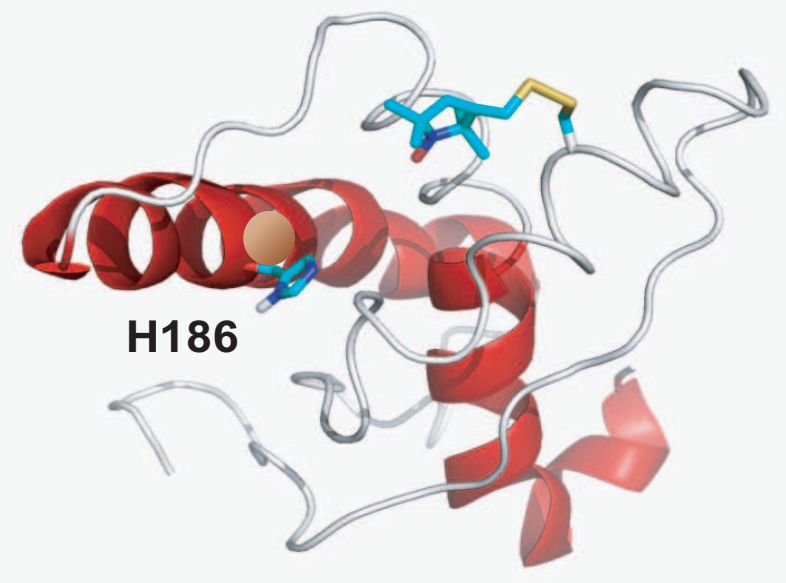

(d) Y156R1

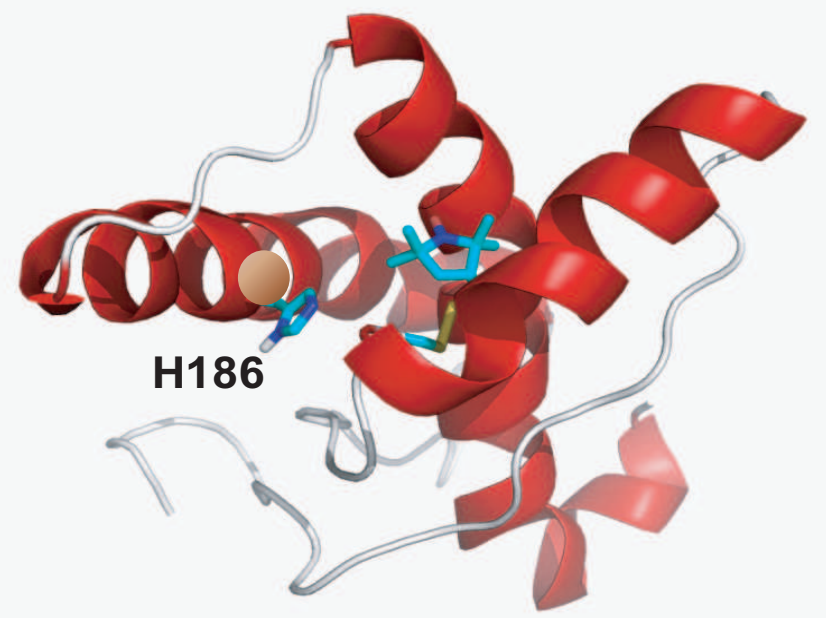

(f)

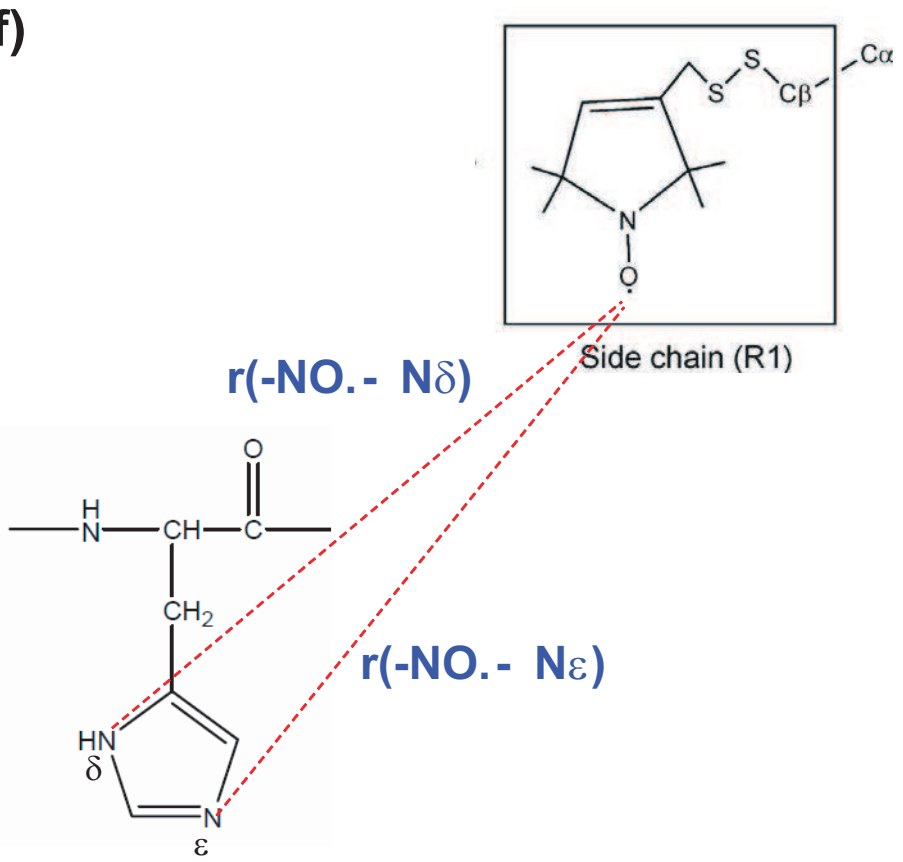

